The International Journal of Indian Psychology

ISSN 2348-5396 (e) | ISSN: 2349-3429 (p)

Volume 5, Issue 1, DIP: 18.01.046/20170501

DOI: $10.25215 / 0501.046$

http://www.ijip.in | October-December, 2017

Research Article

\title{
Russian Validation of Homophobia Scale (HS)
}

\author{
Bogdan Tuziak ${ }^{1 *}$
}

\section{ABSTRACT}

Introduction: A three-factors self-reporting questionnaire, consisting of 25 items, related to behavior/negative affect, affect/behavioral aggression, and negative cognition towards homosexual people, was administered to a sample of 200 farmer workers recruited in various ways from two Bryansk and Kursk regions of Russian Federation. Aim: The objective of this paper is to validate the HS in the Russian sample in Russian language. Methods: A Russian translation of the HS was carried out by two bilingual translators, after which an English native translated the Russian test back into the English language. Main Outcome Measures: Together with the translated version of HS was administrated a biodata questionnaire including the main information as age, level of education, partnership status, faith and sex orientation. Results : Analyzing obtained data of 200 subjects (100 (50\%) female and 100 (50\%) male) with ages ranging from 18 to 50 years (mean age $=21.19 \pm 2.65$; SD: 8.82) showed an overall Cronbach's $\alpha$ coefficient 0.92 of the internal consistency. All three domains had a good alpha coefficient (three higher than .91), whereas in the total score was .87. The test-retest reliability results: behavior/negative affect was $r=0.79(\mathrm{P}<0.0001)$, affect/behavioral aggression was $\mathrm{r}=0.82 \quad(\mathrm{P}<0.0001)$, negative cognition was $\mathrm{r}=0.74$ $(\mathrm{P}<0.0001)$ and the HS total score was $\mathrm{r}=0.93(\mathrm{P}<0.0001)$. Conclusions: This study offers a new tool to assess homophobia in Russian population. The Russian validation of the HS in Russian language revealed the use of this self-report test to have good psychometric properties. Therefore, this scale is a necessary diagnostic instrument to detect subtle homophobic attitudes toward homosexual people and useful in the preventive programs of homophobic behavior, in the clinical praxis.

Keywords: Homophobia, Russia, Homophobia Scale, Russian, LGBT, Psychometrics

Homophobia is defined as the negative feelings, attitudes and fear displayed toward homosexual people [1] or towards "suspected" people in homosexual characteristics. Negative beliefs about homosexuality and homophobic prejudices are present in West society and pervasive in East society [2]. The fact that the homosexual people can develop, adopt towards homosexuality negative feelings and views suggests the higher homophobia level in the heterosexual sample [3], [4], [5]. The homophobic attitudes are appraised from the

\footnotetext{
${ }^{1}$ Department of Biotechnological and Applied Clinical Sciences, University of L'Aquila, L'Aquila, Italy *Responding Author

Received: October 06, 2017; Revision Received: November 01, 2017; Accepted: November 23, 2017 (C) 2017 Tuziak B; licensee IJIP. This is an Open Access Research distributed under the terms of the Creative Commons Attribution License (www.creativecommons.org/licenses/by/2.0), which permits unrestricted use, distribution, and reproduction in any Medium, provided the original work is properly cited.
} 


\section{Russian Validation of Homophobia Scale (HS)}

homophobic information transferred by sociality and mass-media. The individual psychological development consists in adaptation to the social norms, that consists also in accepting of the certain point of view (not complex view) and prejudice socially prepared for thinking facilitation. The homosexual prejudices are negative because they form a distorted LGBT-image causing the irrational fear of sexual diversity and intolerance towards the homosexual people [1], [6].

The fact of aggressive homophobic behavior and its negative consequences conducted to the exclusion of homosexuality from the second edition of the Diagnostic and Statistical Manual of Mental Disorders [7] The aggressive homophobic symptoms as discrimination against homosexual people through psychological and social aversion and, sometimes, as physical violence are called homonegativity, distinguishing this aggressive attitude from the phobia [8]. Regardless, research into homophobia or homonegativity amplified in 1983 after the nosological revisions of the DSM (Diagnostic and Statistical Manual of Mental Disorders). Indeed, that year was characterized by removal of homosexuality from the list of mental health problems, demonstrating more social acknowledgment of homosexuality and homosexuals [8], [9].

In any case, the recurrence of homophobic attitudes have not decreased in individuals, as a signal of the necessity of a correct measurement of homophobia phenomenon [10], [11]. The most oftentimes used instruments evaluating the homophobia development are next: Homophobia Scale (Bouton et al. 1987) [12]; Multidimensional Heterosexism Inventory (Walls 2008) [13]; LGB-KASH (Worthington, Dillon, and Becker-Schutte 2005) [14]; and Modern Homophobia Scale (Raja and Stokers 1998) [15]; and Homophobia Scale (Wright, Adams, and Bernat 1999) [16].

The Homophobia Scale of Bouton et al. was initially composed of 30 items, later reduced to 18, assessed as positive/negative on the 11 points scale. The Homophobia Scale was administered firstly to 528 American under-graduate students. The Modern Homophobia Scale (Raja and Stokers 1998) composed of items gleaned from the scientific literature of the main tests used and was administered to 322 students. The LGB-KASH (Worthington, Dillon, and Becker-Shutte 2005), designed by 32 items; 28 of them was inserted after the pilot study. The Multidimensional Heterosexism Inventory (Walls 2008), for the first time consisted of 44 items taken from the previous version, now consists of 23 items decided upon after analysis of four specific factors. Other significant instrument is the Attitudes toward gays and lesbians designed by 20 items along five-point Likert scale [17], [18].

After analyzing above tools the author considers the Homophobia Scale (Wright, Adams, and Bernat 1999) to be one of the most valid self-report tests for the homophobic construct assessment, because it overcomes the criticism of many scales, assessing the immense range of homophobic aspects in comparison with them [19]. In such manner, a recent systematic review considers the Homophobia Scale a sufficient tool to considering the complex phenomenon of homophobia in a newly and comprehensively [20]. 


\section{Russian Validation of Homophobia Scale (HS)}

The aim of the first validation of the Homophobia Scale was developing and validating its initial psychometric characteristics, and to descript precisely the homophobia aspects such cognitive, affective and behavioral. After its factor analysis, the scale was divided into three subscales: behavior/negative feeling, feeling/behavioral aggression, and negativism cognitive. The HS' development of the in the English language and the related validation was performed on a sample of 321 subjects at its first administration and 122 at the test-retest analysis.

The psychometric properties of the Homophobia Scale were calculated with Cronbach's $\alpha$ coefficient for internal consistency $(\alpha=95.28)$ and the calculation of the test-retest reliability shows that a Pearson coefficient was $r=.958(P<0.01)$. The Pearson coefficient's concurrent validity between the HS and the Index of Homophobia [19] used indicates a high level of correlation $(r=0.658, P<0.01)$. The HS in its final version, validated by Wright, Adams and Bernat (1999) consists of 25 items and assesses three factors: behavior/negative feeling, emotion/aggression behavioral, and cognitive negativism. The high level of homophobia was indicated by higher scores in the total score of the scale. The distribution of the answers represents the five-point Likert scale from "strongly agree” (1) to "strongly disagree” (5).

\section{Aim}

The aim of this study was a translation of the HS from English into Russian and its successive validation in a sample of the Russian population, especially in farm workers of two regions.

\section{METHODS}

\section{Sample Recruitment}

The HS and the socio-demographic questionnaires were given to a pool of 200 farmer workers of two Russian oblast in September 2017. They was heterosexual subjects aged 1850 years, voluntarily decided to participate and without severe mental disorders, that is, mood disorders or psychosis as assessed by a clinical psychologist according to the DSM-V criteria.

\section{Main Outcome Measures}

The Russian translation of the HS and the biodata (like age, level of education partnership status, faith and sex orientation) questionnaire was administered.

\section{Translation}

During the translating process of the Homophobia Scale the Minimal Translation Criteria were followed by two independent bilingual translators for each language [20]. Each item was adapted and evaluated by the author to understanding of the Russian people, especially for the persons with low education level. Final Russian version and back-translated version of the HS were revised and approved with suggestions by one of the original authors, Dr. Lester Wright 


\section{Russian Validation of Homophobia Scale (HS)}

\section{Statistical Analysis}

The data collected were organized in an Excel 2007 spreadsheet, and SAS 9.0 software was used for descriptive and inferential analysis. The continuous variables was presented as mean \pm standard deviation, and categorical variables are expressed as numbers and percentages. Categorical variables were represented as percentage and absolute frequencies. The assessment of the internal consistency was produced by the overall Cronbach's $\alpha$ coefficient following the 25 items of the HS and also for the four domains. In addition, the factorial analysis was employed to test the eigenvalues and the variance. The test-retest reliability was performed by the Pearson coefficient, calculated with two administrations, first at the baseline and then regularly after 14 days (82\%), and after 15-16 days (18\%). The correlation among the factors of HS was carried out. All statistical analyses and reevaluations were carried out using SPSS 20.0 (SPSS Inc., Chicago, IL, USA).

\section{RESULTS}

Overall, data of 200 subjects (range $18-50$ years; mean age $=21.19 \pm 2.65$; SD: 8.82; 100 (50\%) female and 100 (50\%) male) were retrieved for analysis. Socio-demographic characteristics revealed that, among the recruited subjects, there were no differences by gender. Partnership status: 164 (82\%) of subjects were in a relationship. Sexual orientation: $100 \%$ of heterosexuals. Faith: 192 (96\%) of faithfuls. The mean score of the HS was $60.26 \pm 18.13$ (Table 1).

Table 1. Demographic characteristics and scores to Homophobia Scale

\begin{tabular}{|l|l|l|}
\hline & & $\mathbf{n}(\mathbf{\%})$ \\
\hline Age & Mean $=21.19 \pm 2.65$ & $100 ; 100 \%$ \\
\hline & Women & $100(50 \%)$ \\
\hline Partnership status & Men & $100(50 \%)$ \\
\hline & Have a relationship & $164(82 \%)$ \\
\hline Sex orientation & Single & $36(18 \%)$ \\
\hline Faith & Heterosexual & $200(100 \%)$ \\
\hline & Faithful & $126(93 \%)$ \\
\hline Homophobia Scale (mean \pm SD) & Atheist & $74(37 \%)$ \\
\hline & Total score & $60.26 \pm 18.13$ \\
\hline & Behavior/negative affect & $23.28 \pm 7.12$ \\
\hline & Affect/behavioral aggression & $22.67 \pm 6.52$ \\
\hline & Negative cognition & $14.26 \pm 4.49$ \\
\hline
\end{tabular}

\section{Table 1 Demographic characteristics and scores to Homophobia Scale}

Soon after the extraction and rotation, we considered the eigenvalues higher of one, and the variance explained was of $68.1 \%$. The internal consistency analysis showed an overall Cronbach's $\alpha$ coefficient was of 0.92 . The three subscales presented the Cronbach's $\alpha$ coefficient 0.91 in behavior/negative affect, 0.93 in affect/behavioral aggression, and 0.92 in negative cognition, whereas in the total score was 0.87 . (Table 2 ). 
Table 2. Internal consistency of the Homophobia Scale in Russian sample $(\mathrm{n}=200)$

\begin{tabular}{|l|l|}
\hline Domains of Homophobia Scale and overall internal consistency & Cronbach's $\boldsymbol{\alpha}$ \\
\hline Behavior/negative affect & 0.91 \\
\hline Affect/behavioral aggression & 0.93 \\
\hline Negative cognition & 0.92 \\
\hline HS total score & 0.87 \\
\hline Overall Cronbach's $\alpha$ & 0.92 \\
\hline
\end{tabular}

Table 2 Internal consistency of the Homophobia Scale in Russian sample $(n=200)$

For the test-retest reliability, the author assessed 200 and analyzed the Pearson coefficient related to the total score and the three subscales. The test-retest analysis had two administrations, one at the baseline and one after 14 and 15 days for the absents. The author founded a significant and positive correlation in the four domains of the HS after the testretest analysis. In particular, the HS total score was $r=0.93 \quad(P<0.0001)$, the behavior/negative affect was $r=0.79 \quad(P<0.0001)$, the affect/behavioral aggression was $r=0.82(P<0.0001)$, and the negative cognition was $r=0.74(P<0.0001)$ (Table 3$)$.

Table 3. Test-retest reliability $(n=200)$

\begin{tabular}{|l|l|}
\hline Domains of Homophobia Scale & Pearson coefficient \\
\hline HS total score & $0.93^{*}$ \\
\hline Behavior/negative affect & $0.79 *$ \\
\hline Affect/behavioral aggression & $0.82^{*}$ \\
\hline Negative cognition & $0.74^{*}$ \\
\hline$* \mathrm{P}<0.0001$ &
\end{tabular}

Table 3 Test-retest reliability $(n=200)$

Moreover, as shown in Table 4, we can see the positive correlation among the HS domains. Each of the domains positively correlate with another domain of the HS, for example, the behavior/negative affect has a positive correlation with affect/behavioral aggression $(r=0.65 ; P<0.0001)$, with negative cognition $(r=0.77 ; P<0.0001)$, and with the total score of the HS $(r=0.93 ; P<0.0001)$. In addition, affect/behavioral aggression correlates positively with negative cognition $(r=0.60 ; P<0.0001)$ and with the total score of the HS $(r=0.83 ; P<0.0001)$, and negative cognition has a positive association with the total score of the HS $(r=0.87 ; P<0.0001)$.

Table 4. Correlation among the domains of Homophobia Scale

\begin{tabular}{|l|l|l|l|l|}
\hline & $\begin{array}{l}\text { Behavior/negative } \\
\text { affect }\end{array}$ & $\begin{array}{l}\text { Affect/behavioral } \\
\text { aggression }\end{array}$ & $\begin{array}{l}\text { Negative } \\
\text { cognition }\end{array}$ & $\begin{array}{l}\text { HS total } \\
\text { score }\end{array}$ \\
\hline Behavior/negative affect & $\backslash$ & $0.65^{*}$ & $0.77^{*}$ & $0.93^{*}$ \\
\hline Affect/behavioral aggression & $\backslash$ & $\backslash$ & $0.60^{*}$ & $0.83^{*}$ \\
\hline Negative cognition & $\backslash$ & $\backslash$ & $\backslash$ & 0.87 \\
\hline$* \mathrm{P}<0.0001$ & &
\end{tabular}

Table 4 Correlation among the domains of Homophobia Scale 
In the Appendix 1 is shown the usefulness of the Russian version of HS* in Russian language and it's scoring as a psychometric instrument.

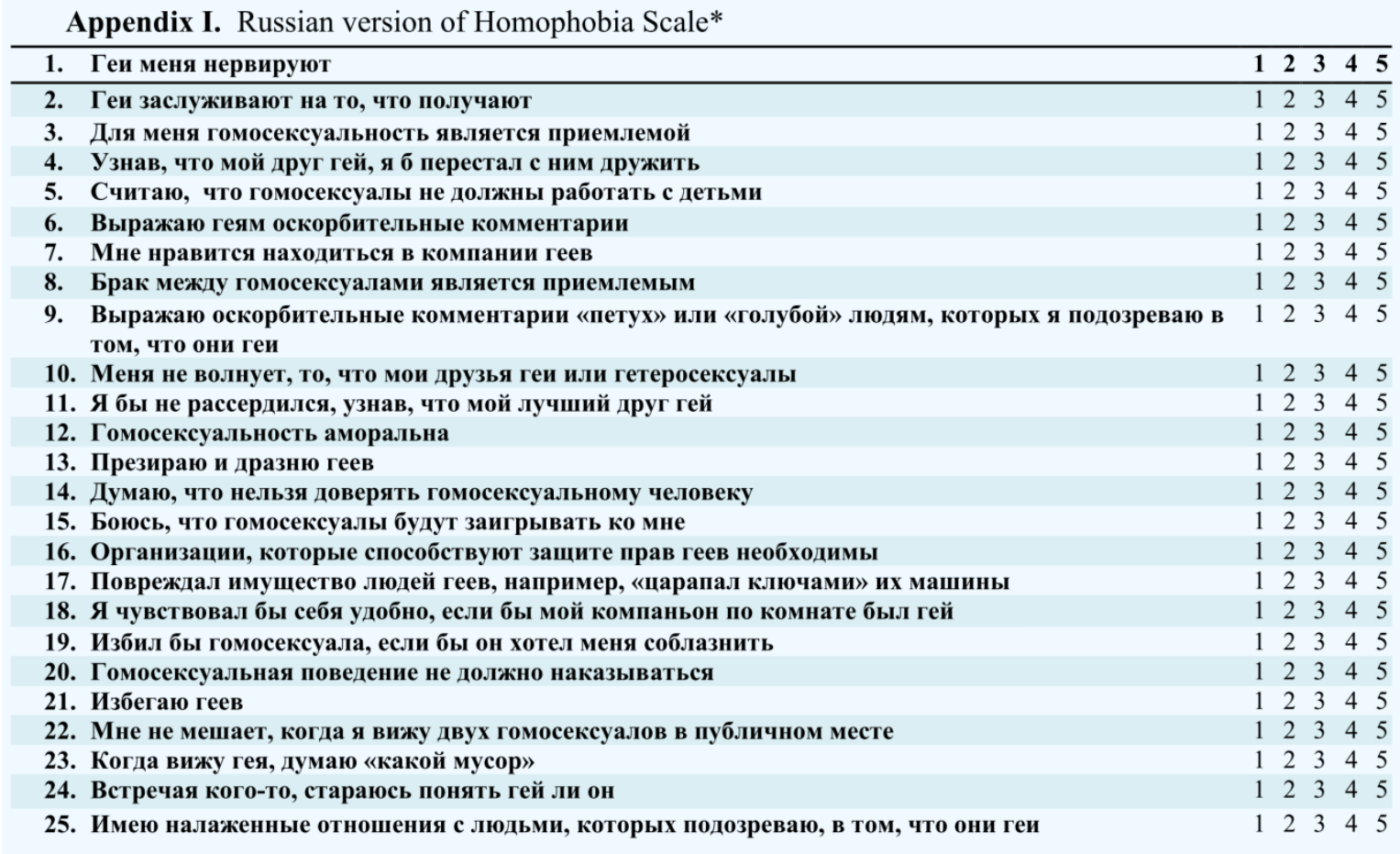

\section{DISCUSSION}

The study consisted in the first translation and validation of the Russian HS in the Russian language. During this study was analyzed its implementation of the assessment of phobic behavior against homosexuals in both research and clinical contexts.

After validation of the HS emerges the high administrating, items' understanding qualities and good psychometric characteristics of this psychometric instrument, incentivizing the use of HS in Russian Federation.

The assessment with Cronbach's $\alpha$ of the internal consistency revealed high values for the overall coefficient and also in the four subscales. Such as in the original version of Homophobia Scale has been explained about $70 \%$ of the variance [16] and the test-retest reliability demonstrated another positive characteristic regarding the validity of this test, such as the correlation coefficients among the scales. All these psychometric elements contribute to the HS and should incentivize it's use in Russian Federation, especially in Russian speaking subjects [21]. The homophobic behaviors are more present and episodes of denigration or violence toward homosexual people are more frequent in the Russian population than in Europe countries’ population [23], [24].

Numerous LGBT-rights associations promote preventive programs toward violence, discrimination, and homophobic bullying in many public institutions, in schools for create a culture of respect and equality, also from a judicial point of view [25]. 


\section{Russian Validation of Homophobia Scale (HS)}

In any case, adequate tools for the assessment of homophobia in Russia are absent and the HS is the first psychometric instrument actually validated in Russian sample.

The author assumes that the assessment of such specific domains of the Russian HS as behavior/negative affect, affect/behavior aggression, and negative cognition could be very useful for the measurement and studying of homophobia by clinics and researchers in a subject or in an entire study population. These domains evaluates the behaviors, specific feelings, emotional arousal linked to homosexual people and to homosexuality [26].

There are researchers investigated the unchecked psychological mechanisms related to homophobia involving a conservative culture and anger [27], [28]. These aspects with specific items with integration among the psychological, cultural, and emotional factors that contribute to homophobic behavior are also investigated by the Homophobia Scale.

The potential offenders and victims can have the benefits only in case of the precise assessment of potential homophobic tendencies [6]: preventing the deviant behavior in offenders, such as abuse of substances, generalized violence and preventing the potential victims of psychological or physical aggression.

Furthermore, the homophobia assessment and the diffusion of this praxis can indirectly improve the social perception of homosexuality and related aspects. In fact, homosexual people are greatly influenced by a homophobic society, and this contributes to the phenomenon of internalized homophobia in homosexuals. Several studies point out that internalized homophobia causes depression, distress, and suicide [29], [30], [31], [32].

The goals of a free society are psychological and physical health and rights of homosexuals and the individuation of deviant behaviors as homophobia is a desirable capacity that each operator in educational and care contexts should know. There're different researches investigating the approach of physicians and nurses to homosexuals [33], [34], with some disagreeable surprises [35], [36]. Consequently, it is also indispensable to activate adequate programs of prevention of homophobia among experts in sexuality, as psychologists and gender rights defenders, in various social areas, and to introduce the HS into the development of these prevention programs.

\section{CONCLUSION}

The assessment of homophobia is an essential issue in the safeguarding of the psychological, social, and physical health of homosexuals. The author concluded that the Russian version of HS can be used in routine psychological practice as a reliable diagnostic instrument for the estimation of homophobic attitudes experienced by a patient in specific contexts, such as health institutions, workplaces, universities, religious institutions and schools. Also the HS can be used for monitoring efficiency of psychotherapy and in mental disorders research. 


\section{Russian Validation of Homophobia Scale (HS)}

\section{Acknowledgments}

The author thanks Dr. Lester Wright for comments, suggestions and permissions.

\section{Conflict of Interest}

The author report no conflicts of interest.

\section{Supporting Information}

Tables: 1, 2, 3, 4; Appendix 1 (Russian version of Homophobia Scale*).

\section{REFERENCES}

1. Weinberg G. Society and the healthy homosexual. New York: St. Martin's Press; 1972. Homophobia; pp. 20-29.

2. Savin-Williams RC. Then and now: recruitment, definition, diversity, and positive attributes of same-sex populations. Dev Psychol. 2008;44(1):135-8. doi: 10.1037/0012-1649.44.1.135.

3. Malyon, A. K. (1982). Psychotherapeutic implications of internalized homophobia in gay men. Journal of Homosexuality, 7, 59-70.

4. Forstein, M. (1988). Homophobia: An overview. Psychiatric Annals, 18, 33-36.

5. Gonsiorek, J. C. (1982). The use of diagnostic concepts in working with gay and lesbian populations. Journal of Homosexuality, 7, 9-20.

6. Kantor M., Homophobia: Description, development, and dynamics of gay bashing. Westport, CT: Praeger; 1998. Homophobia psycological aspects; p. 175.

7. APA. Diagnostic and statistical manual of mental disorders. 3th edition. Washington: APA; 1980.

8. Lingiardi V, Nardelli N. Negative attitudes to lesbians and gay men: Persecutors and victims. In: Giovanni Corona EAJ, Maggi M. editors. Emotional, physical and sexual abuse. Switzerland: Springer; 2014. pp. 33-47.

9. Jannini EA, Blanchard R, Camperio-Ciani A, Bancroft J. Male homosexuality: Nature or culture?J Sex Med. 2010;7:3245-3253.

10. Wright LW, Jr, Adams HE, Bernat J. Homophobia scale. In: Fisher TD, Davis CM, Yarber WL, Davis SL, editors. Handbook of sexuality-related measures. UK: Routledge; 2013. pp. 402-404.

11. Grey JA, Robinson BB, Coleman E, Bockting WO. A systematic review of instruments that measure attitudes toward homosexual men. J Sex Res. 2013;50:329_ 352.

12. Bouton RA, Gallaher PE, Garlinghouse PA, Leal T, Rosenstein LD, Young RK. Scales for measuring fear of AIDS and homophobia. J Pers Assess. 1987;51:606614.

13. Walls NE. Toward a multidimensional understanding of heterosexism: The changing nature of prejudice. J Homosex. 2008;55:20-70.

14. Worthington RL, Dillon FR, Becker-Schutte AM. Development, reliability, and validity of the lesbian, gay, and bisexual knowledge and attitudes scale for heterosexuals (LGB-KASH) J Couns Psychol.2005;52:104-118. 
15. Raja S, Stokes JP. Assessing attitudes toward lesbians and gay men: The modern homophobia scale.Int J Sex Gend Stud. 1998;3:113-134.

16. Wright LW, Adams HE, Bernat J. Development and validation of the homophobia scale. J Psychopathol Behav Assess. 1999;21:337-347.

17. Herek GM. Heterosexuals' attitudes toward lesbians and gay men: Correlates and gender differences. J Sex Res. 1988;25:451-477.

18. Herek GM, Capitanio JP. Conspiracies, contagion, and compassion: Trust and public reactions to AIDS. AIDS Educ Prev. 1994;6:365-375.

19. O'Donohue W, Caselles CE. Homophobia: Conceptual, definitional, and value issues. J Psychopathol Behav Assess. 1993;15:177-195.

20. Costa AB, Bandeira DR, Nardi HC. Systematic review of instruments measuring homophobia and related constructs. J Appl Soc Psychol. 2013;43:1324-1332.

21. Hudson WW, Ricketts WA. A strategy for the measurement of homophobia. J Homosex.1980;5:357-372.

22. Medical outcomes trust: Trust introduces new translation criteria. Trust Bull 1997;5:3-4

23. Tamara Martsenyuk, The State of the LGBT Community and Homophobia in Ukraine, Problems of Post-Communism Vol. 59, Iss. 2, 2012

24. G. Ciocca, C. Niolu, D. Déttore, P. Antonelli, S. Conte, B. Tuziak, E. Limoncin, D. Mollaioli, E. Carosa, G. L. Gravina,S. Di Sante, G. Di Lorenzo, A. D. Fisher, M. Maggi, A. Lenzi, A. Siracusano, E. A. Jannini. (2017) Cross-cultural and sociodemographic correlates of homophobic attitude among university students in three European countries. Journal of Endocrinological Investigation 40:2, pages 227-233.

25. Prati G, Coppola M, Saccà F. Report Finale della ricerca nazionale sul bullismo omofobico nelle scuole superiori italiane. Arcigay, Associazione lesbica e gay italiana. 2010:1-92.

26. Davies M. Correlates of negative attitudes toward gay men: Sexism, male role norms, and male sexuality. J Sex Res. 2004;41:259-266.

27. Ernulf KE, Innala SM. The relationship between affective and cognitive components of homophobic reaction. Arch Sex Behav. 1987;16:501-509.

28. Ernulf KE, Innala SM, Whitam FL. Biological explanation, psychological explanation, and tolerance of homosexuals: A cross-national analysis of beliefs and attitudes. Psychol. Rep.1989;65:1003-1010.

29. Gibbs JJ. Religious Conflict, Sexual Identity, and Suicidal Behaviors among LGBT Young Adults. Archives of suicide research: official journal of the International Academy for Suicide Research. 2015;19(4):472-488. doi:10.1080/13811118.2015.1004476.

30. Baiocco R, Ioverno S, Cerutti R, Santamaria F, Fontanesi L, Lingiardi V, Baumgartnert E, Laghi F. Suicidal ideation in Spanish and Italian lesbian and gay young adults: The role of internalized sexual stigma. Psicothema. 2014;26:490-496.

31. Baiocco R, Ioverno S, Lonigro A, Baumgartner E, Laghi F. Suicidal ideation among Italian and Spanish young adults: The role of sexual orientation. Arch Suicide Res. 2014;19:75-88. 


\section{Russian Validation of Homophobia Scale (HS)}

32. McLaren S. Gender, age, and place of residence as moderators of the internalized homophobia-depressive symptoms relation among Australian gay men and lesbians. J Homosex. 2014;62:463-480.

33. Lingiardi V, Capozzi P. Psychoanalytic attitudes towards homosexuality: An empirical research. Int J Psychoanal. 2004;85:137-157.

34. Rager Zuzelo P. Improving nursing care for lesbian, bisexual, and transgender women. J Obstet Gynecol Neonatal Nurs. 2014;43:520-530. Quiz E40-1.

35. Koh CS, Kang M, Usherwood T. "I demand to be treated as the person I am": Experiences of accessing primary health care for Australian adults who identify as gay, lesbian, bisexual, transgender or queer. Sex Health. 2014;11:258-264.

36. Campo-Arias A, Herazo E, Cogollo Z. [Homophobia among nursing students] Rev Esc Enferm USP. 2010;44:839-843.

How to cite this article: Tuziak B (2017). Russian Validation of Homophobia Scale (HS). International Journal of Indian Psychology, Vol. 5, (1), DIP: 18.01.046/20170501, DOI: $10.25215 / 0501.046$ 